\title{
EFFECT OF PROCESS PARAMETERS ON MACHINING PROCESS USING SINGLE POINT CUTTING TOOL: AN ANOVA ANALYSIS BASED STUDY
}

\author{
Md. Khursheed Alam and Dr. Ravi Kumar Goyal \\ Mechanical Department, Jaipur Institute of Technology-Group of Institutions, Jaipur, \\ Rajasthan, India
}

\begin{abstract}
This research work studies the basic influence of cutting process parameters used in single point cutting tool based on machining operations. In this study design of experiment methodology is used for some qualitative outcome. Taguchi method is used for experiment design. L16 orthogonal array is solved using ANSYS Explicit Dynamics software. ANOVA analysis is performed using Minitab software. Results show that most critical factor which affects stress generated during cutting operations are rake angle of tool and feed rate. In this study model equations are also generated for further analysis using linear regression modeling technique using Minitab software.
\end{abstract}

\section{KEYWORDS}

Single point cutting tool, ANOVA, orthogonal array, FEM, explicit dynamics

\section{INTRODUCTION}

Machining is the process of gradual removal of metal from a work piece in the form of chips to obtain specified geometrical dimension and the surface finished by using single and multipoint cutting tool. The metal cutting process is the very complex process and its complexity is mostly because of the problematic chip formation. Now a day advancement in new manufacturing process, the conventional machining processes are the most common manufacturing process. It involves with high stress and strain which must be known to improve all of the process. In recent years Finite Element Method (FEM) based on Eulerian and updated Lagrangian formulation has been developed to analyse the Machining process. The Eulerian formulation is applied in many of FEM models used for orthogonal metal cutting. Finite Element technique such as element separation criterion, the modeling of cutting tool wear, re-meshing zone and friction modeling are applied to improve accuracy and efficiency of Finite Element Method in metal cutting process. The cutting condition and quality of machining operation can be determined by understanding the characteristics of metal removal process. A single point cutting tool has one sharp cutting edge and used for turning boring and planning. The cutting tool is made by material harder than the work piece. The cutting edge separates the chip from the work material to impart the required size and shape of work piece. The cutting tools are used as a rigid body and it moves horizontally with the variable speed into the work piece. It also set a suitable cutting condition like cutting velocity, feed and depth of cut. The cutting velocity, feed rate and depth of cut are from the three dimensions of the machining process and their products are used to obtain material removal rate. 


\section{NUMERICAL SIMULATION AND PROBLEM IDENTIFICATION}

ANSYS Explicit Dynamics 14.5 is a complete suite of perfect tools for simulating, analyzing, optimizing and validating machining products used in various industrial field. This software addresses the broadest range of manufacturing issues and design geometry types associated with machining processes.

There are three stages of the simulation in Explicit Dynamics. The first stage of a Finite Element (FE) method based simulation is called "pre-process". It can be also performed by using the simulation software by itself or one of the Computer-Aided Design (CAD) on computer programs such as Autodesk Inventor, and Auto-cad. Then geometric model is meshed using triangular mesh elements which is automatic mesh generation. Afterwards, the desired material (Al6061) is selected and tool location is set for simulation which is treated as rigid material. For finishing this first stage, it is also required to set the process conditions on the simulation software. Further in the second stage of a simulation process, there are various governing equations are performed and applied to a model analysis. The last stage of a FEM simulation is called "post-process", where the experience of the analyst is required to extract the reliable and most important information from multiples colored contour results offered by the simulation software Pre-process is very important for the efficiency of the simulation model. Hence, it must be thoroughly analyzed on the part geometry and its conditions as described in the following section. In table 1 material properties of $\mathrm{Al} 6061$ is presented.

TABLE 1 Properties of Al6061

\begin{tabular}{|c|c|c|}
\hline Property & Value & Unit \\
\hline Density & 2703 & $\mathrm{Kg} / \mathrm{m} 3$ \\
\hline Sp. Heat & 885 & $\mathrm{~J} / \mathrm{kgC}$ \\
\hline Steinberg Guinean Strength & & \\
\hline Initial Yield Stress & $2.9 \mathrm{E}+08$ & $\mathrm{~Pa}$ \\
\hline Max Yield Stress & $6.8 \mathrm{E}+08$ & $\mathrm{~Pa}$ \\
\hline Hardening Constant & 125 & $\mathrm{NA}$ \\
\hline Hardening Exponents & 0.1 & $\mathrm{NA}$ \\
\hline Derivative dG/dP & 1.8 & $\mathrm{NA}$ \\
\hline Derivative dG/dT & $-1.7 \mathrm{E}+07$ & $\mathrm{~Pa} / \mathrm{C}$ \\
\hline Derivative dY/dP & 0.018908 & $\mathrm{NA}$ \\
\hline Melting Temperature & 946.85 & $\mathrm{C}$ \\
\hline Shear Modulus & $2.76 \mathrm{E}+10$ & $\mathrm{~Pa}$ \\
\hline Shock EOS Linear & & \\
\hline Gruneisen Coefficient & 1.97 & $\mathrm{NA}$ \\
\hline Parameter C1 & 5240 & $\mathrm{~m} / \mathrm{s}$ \\
\hline Parameter S1 & 1.4 & $\mathrm{NA}$ \\
\hline Parameter Quadratic S2 & 0 & $\mathrm{~s} / \mathrm{m}$ \\
\hline
\end{tabular}

\section{Problem description}

The problem has been discussed and focused in this study by apply the Computer Aided Engineering methods in single point cutting process parameter to improve the productivity of machining based products. There are three controlling factors named cutting speed, feed rate and 
rake angle are used with four levels and taguchi tables are also used for design of experiment in this study, which is shown in table 2 and 3 . Figure 1 show CAD file of problem used in this study.

Table 2 Summary of all levels and their factors

\begin{tabular}{|c|c|c|c|}
\hline $\begin{array}{c}\text { Factor/ } \\
\text { Level }\end{array}$ & $\begin{array}{c}\text { Cutting Speed } \\
(\mathbf{m} / \mathbf{m i n})\end{array}$ & Feed Rate (mm) & Rake Angle \\
\hline 1 & 250 & 0.6 & 0.0 \\
\hline 2 & 500 & 0.8 & 2.5 \\
\hline 3 & 750 & 1.0 & 5.0 \\
\hline 4 & 1000 & 1.2 & 7.5 \\
\hline
\end{tabular}

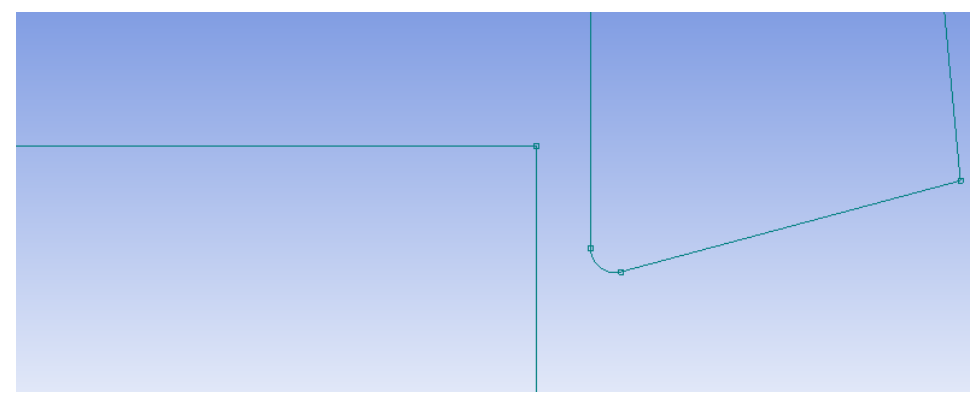

Fig. 1 (a) Single Point Cutting tool at zero degree angle

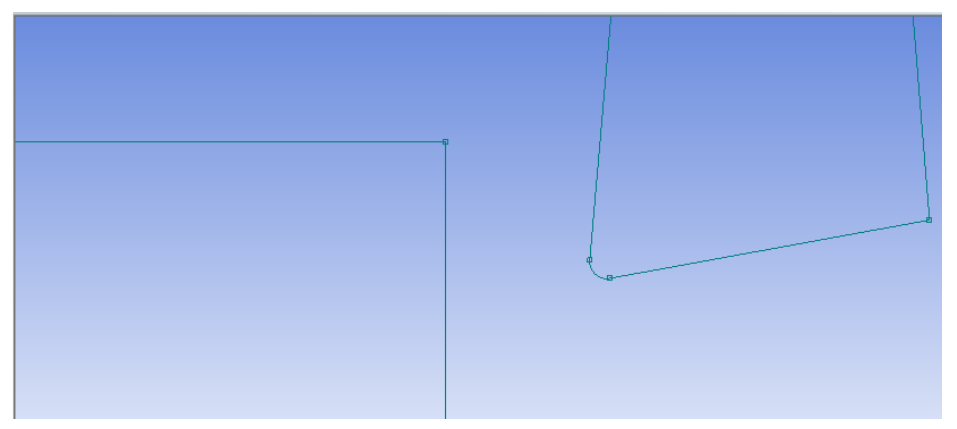

Fig. 1 (b) Single Point Cutting tool at five degree angle

\section{DESIGN OF EXPERIMENT AND RESEARCH METHODOLOGY}

The effects of process parameters are studied by various researchers from last decades. It is difficult to design the experiments for any type of research so here is a scientific approach which is helpful for researchers which is known as the "DESIGN OF EXPERIMENT". This technique is adopted by researcher for this study. By use of D.O.E. techniques any researcher can determine important factors which are responsible for output result variation of experiments. DOE can found optimum solution for particular experiments. In this study taguchi methods are used for ANOVA analysis. Factor and levels are shown in table 2. After selection of factors and levels for current study, it is very important to select the accurate orthogonal array and for this work MINITAB software is used for making of orthogonal array of factors and their levels which are shown in table 3. 
Table 3 L16 Orthogonal array

\begin{tabular}{|c|c|c|c|}
\hline Sr. No. & cutting_speed & Feed_Rate & Rake_Angle \\
\hline 1 & 250 & 0.6 & 0 \\
\hline 2 & 250 & 0.8 & 2.5 \\
\hline 3 & 250 & 1 & 5 \\
\hline 4 & 250 & 1.2 & 7.5 \\
\hline 5 & 500 & 0.6 & 2.5 \\
\hline 6 & 500 & 0.8 & 0 \\
\hline 7 & 500 & 1 & 7.5 \\
\hline 8 & 500 & 1.2 & 5 \\
\hline 9 & 750 & 0.6 & 5 \\
\hline 10 & 750 & 0.8 & 7.5 \\
\hline 11 & 750 & 1 & 0 \\
\hline 12 & 750 & 1.2 & 2.5 \\
\hline 13 & 1000 & 0.6 & 7.5 \\
\hline 14 & 1000 & 0.8 & 5 \\
\hline 15 & 1000 & 1 & 2.5 \\
\hline 16 & 1000 & 1.2 & 0 \\
\hline
\end{tabular}

After design of DOE table it is important to find out significance of input parameters with output results and here ANOVA analysis is applicable. Some steps are followed during ANOVA analysis using Minitab software.

\section{RESULT AND DISCUSSION}

Single point cutting process is simulated in this study for one design cases which is shown in figure 1. ANSYS Explicit Dynamics FEM package is used for simulation purpose. All the experiments are designed according to Design of Experiment technique (Taguchi orthogonal array table), which are also presented in table 2 and 3. The main outcomes focused in this study are following:

\subsection{ANOVA Analysis}

The main output from an analysis of variance study is to arrange a table. List the sources of variation, and their degrees of freedom, the total sum of squares, and the mean squares. The analysis of variance table also includes the F-statistics and p-values. Use these to determine and find out whether the predictors or factors are significantly related to the response. ANOVA tables are also used in regression and Design of Experiment analysis. The Source indicates the source of variation, from the factor, the interaction, or the error. The total is a sum of all the sources. DF is the degrees of freedom from each source. If the factor has three levels, then the degrees of freedoms are $2(n-1)$. Such as if you have a total of 30 observations, the degrees of freedom total is $29(n-1)$. 
The $\mathrm{F}$ is calculate by dividing the factor MS by the error MS; you can compare this ratio against a critical $\mathrm{F}$ found in a table or you can use the $\mathrm{p}$-value to determine whether a factor is significant or not.

$\mathrm{P}$ is also use to determine whether a factor is significant; typically compare against an alpha value of 0.05 . Hence it is found that if the p-value is lower than 0.05 , then the factor is significant.

- Signal to noise ratios analysis

- Model equations generation

In this research study response is von-misses stresses (MPa) developed when the cutting process is selected, and all results are according to L16 array experiments are presented in table 4.

Table 4 Response result from FEM code simulation

\begin{tabular}{|c|c|c|c|c|}
\hline Sr. No. & cutting speed & Feed Rate & Rake Angle & Stress \\
\hline 1 & 250 & 0.6 & 0 & 393.4 \\
\hline 2 & 250 & 0.8 & 2.5 & 395.2 \\
\hline 3 & 250 & 1 & 5 & 402.7 \\
\hline 4 & 250 & 1.2 & 7.5 & 408.6 \\
\hline 5 & 500 & 0.6 & 2.5 & 400.08 \\
\hline 6 & 500 & 0.8 & 0 & 397.4 \\
\hline 7 & 500 & 1 & 7.5 & 403.6 \\
\hline 8 & 500 & 1.2 & 5 & 405.1 \\
\hline 9 & 750 & 0.6 & 5 & 403.8 \\
\hline 10 & 750 & 0.8 & 7.5 & 405.1 \\
\hline 11 & 750 & 1 & 0 & 402.6 \\
\hline 12 & 750 & 1.2 & 2.5 & 403.1 \\
\hline 13 & 1000 & 0.6 & 7.5 & 404.1 \\
\hline 14 & 1000 & 0.8 & 5 & 401.2 \\
\hline 15 & 1000 & 1 & 2.5 & 404.7 \\
\hline 16 & 1000 & 1.2 & 0 & 402.1 \\
\hline
\end{tabular}

Minitab software is used for ANOVA analysis in this study. Summary table of three factors and their levels is presented in table 2.

\section{Signal to Noise Ratio}

The Signal to noise ratio is a simple technique to predict the effect of changing of factors according to their levels to find out effect on product quality. In the study "smaller is better" option is adopted as a quality indicator for S/N ratio and means ratio. The response tables for S/N ratio and mean are presented in table 5 and 6 .

Table 5 response table for signal to noise ratio

\begin{tabular}{|c|c|c|c|}
\hline Level & cutting speed & Feed Rate & Rake Angle \\
\hline 1 & -52.04 & -52.05 & -52.02 \\
\hline 2 & -52.07 & -52.03 & -52.06 \\
\hline 3 & -52.12 & -52.11 & -52.11 \\
\hline 4 & -52.11 & -52.14 & -52.16 \\
\hline
\end{tabular}


International Journal of Recent advances in Mechanical Engineering (IJMECH) Vol.4, No.3, August 2015

\begin{tabular}{|c|c|c|c|}
\hline Delta & 0.08 & 0.11 & 0.14 \\
\hline Rank & 3 & 2 & 1 \\
\hline
\end{tabular}

Both tables are showing factors importance ranking and it is very clear that rake angle is most important factor, which can reduce the von-misses stress magnitude during cutting process.

Table 6 response table for mean ratio

\begin{tabular}{|c|c|c|c|}
\hline Level & cutting speed & Feed Rate & Rake Angle \\
\hline 1 & 400.0 & 400.3 & 398.9 \\
\hline 2 & 401.5 & 399.7 & 400.8 \\
\hline 3 & 403.6 & 403.4 & 403.2 \\
\hline 4 & 403.0 & 404.7 & 405.8 \\
\hline Delta & 3.7 & 5.0 & 6.5 \\
\hline Rank & 3 & 2 & 1 \\
\hline
\end{tabular}

Best and worst cases from experiment factors and their levels are also presented in this research study and are calculated from figure 2 and 3.

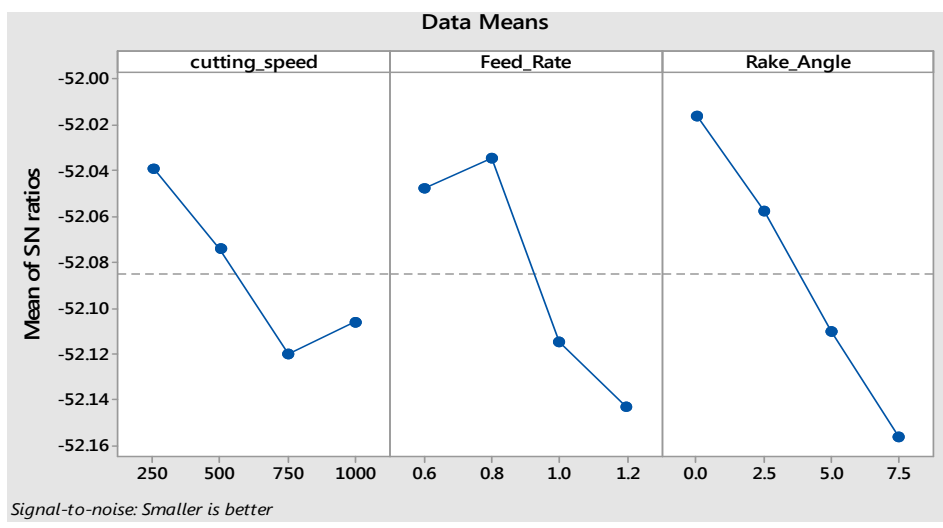

Fig. 1 Data means for smaller is better for $\mathrm{S} / \mathrm{N}$ ratios

Best case: A1 B2 C1

Worse Case: A3 B4 C4

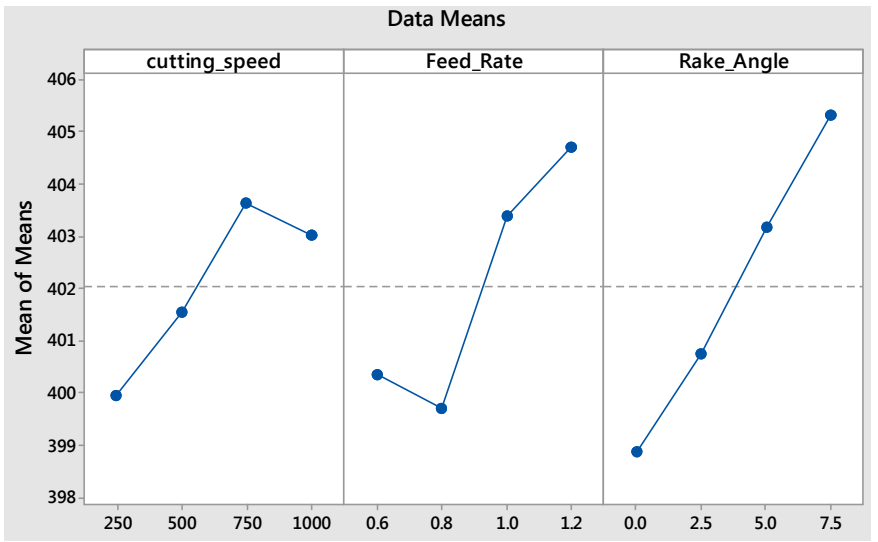


Fig. 2 Data means for mean ratios

Best case: A1 B2 C1

Worse Case: A3 B4 C4

Here A, B and C represent factor cutting speed, feed rate and rake angle respectively.

ANOVA Analysis

In this study the analysis of variance is calculated and results are shown in table 7 respectively. In the ANOVA analysis F-Test is also conduct to compare a model variance with a residual variance. The $\mathrm{F}$ value is calculated from a model mean square divided by residual mean square value. If $\mathrm{F}$ value is approaching to one means then both variances are same, according to $\mathrm{F}$ value highest is best to find critical input parameter.

Table 7 Analysis of Variance for Stress response

\begin{tabular}{|c|c|c|c|c|c|}
\hline Source & DF & Adj SS & Adj MS & F-Value & P-Value \\
\hline Regression & 3 & 177.41 & 59.137 & 14.03 & 0.000 \\
\hline Cutting Speed & 1 & 25.34 & 25.335 & 6.01 & 0.031 \\
\hline Feed rate & 1 & 56.55 & 56.549 & 13.41 & 0.003 \\
\hline Rake Angle & 1 & 95.53 & 95.528 & 22.66 & 0.000 \\
\hline Error & 12 & 50.59 & 4.216 & & \\
\hline Total & 15 & 228.00 & & & \\
\hline
\end{tabular}

Table 7 list out the one important result that $\mathrm{F}$ value for regression models is greater than one and $\mathrm{P}$ value is very less (approx 0.0000). This two values suggested that all cases are significant.

From literature review there are various researchers found that if $\mathrm{p}$ value is very small (less than 0.05 ) then the terms in the regression model have a significant effect to the responses.

ANOVA analysis is also tell that rake angle has very low $\mathrm{p}$ value than other factor like cutting speed and feed rate, although all three factors have acceptable $\mathrm{p}$ value so it can concluded that von-misses stress can be reduced by all factors. This ANOVA analysis is linear single factor analysis, multi product ANOVA analysis can show more accurate results, which are presented in table 8 , but not show good agreement for this study.

Table 8 Analysis of Variance (Square and 2 way) for Stress response

\begin{tabular}{|c|c|c|c|c|c|}
\hline Source & DF & Adj SS & Adj MS & F-Value & P-Value \\
\hline Model & 9 & 210.765 & 23.4183 & 8.15 & 0.009 \\
\hline Linear & 3 & 26.774 & 8.9247 & 3.11 & 0.110 \\
\hline Cutting Speed & 1 & 13.418 & 13.4180 & 4.67 & 0.074 \\
\hline Feed Rate & 1 & 1.770 & 1.7704 & 0.62 & 0.462 \\
\hline Rake Angle & 1 & 11.586 & 11.5856 & 4.03 & 0.091 \\
\hline Square & 3 & 8.666 & 2.8887 & 1.01 & 0.453 \\
\hline $\begin{array}{l}\text { Cutting speed } \\
\text { *Cutting Speed }\end{array}$ & 1 & 4.818 & 4.8180 & 1.68 & 0.243 \\
\hline Feed Rate* Feed Rate & 1 & 3.783 & 3.7830 & 1.32 & 0.295 \\
\hline $\begin{array}{l}\text { Rake Angle * Rake } \\
\text { Angle }\end{array}$ & 1 & 0.065 & 0.0650 & 0.02 & 0.885 \\
\hline 2-Way Interaction & 3 & 24.687 & 8.2289 & 2.86 & 0.126 \\
\hline $\begin{array}{c}\text { Cutting Speed*Feed } \\
\text { Rate }\end{array}$ & 1 & 8.852 & 8.8521 & 3.08 & 0.130 \\
\hline $\begin{array}{c}\text { Cutting Speed*Rake } \\
\text { Angle }\end{array}$ & 1 & 15.128 & 15.1279 & 5.27 & 0.062 \\
\hline
\end{tabular}


International Journal of Recent advances in Mechanical Engineering (IJMECH) Vol.4, No.3, August 2015

\begin{tabular}{|c|c|c|c|c|c|}
\hline $\begin{array}{c}\text { Feed Rate*Rake } \\
\text { Angle }\end{array}$ & 1 & 0.707 & 0.7068 & 0.25 & 0.637 \\
\hline Error & 6 & 17.233 & 2.8722 & & \\
\hline Total & 15 & 227.998 & & & \\
\hline
\end{tabular}

Model equations for von-miss stress are presented in table 9 and table 10 for linear and 2 way ANOVA analysis with model equations.

Table 9 Model summary for ANOVA analysis

\begin{tabular}{|c|c|c|c|}
\hline S & R-sq & R-sq(adj) & R-sq(pred) \\
\hline 2.05317 & $77.81 \%$ & $72.27 \%$ & $60.95 \%$ \\
\hline
\end{tabular}

\section{Coefficients}

\begin{tabular}{|c|c|c|c|c|c|}
\hline Term & Coef & SE Coef & T-Value & P-Value & VIF \\
\hline Constant & 388.39 & 2.51 & 154.45 & 0.000 & \\
\hline Cutting Speed & 0.00450 & 0.00184 & 2.45 & 0.031 & 1.00 \\
\hline Feed Rate & 8.41 & 2.30 & 3.66 & 0.003 & 1.00 \\
\hline Rake Angle & 0.874 & 0.184 & 4.76 & 0.000 & 1.00 \\
\hline
\end{tabular}

\section{Model Equation}

Stress $=388.39+0.00450$ Cutting Speed +8.41 Feed Rate +0.874 Rake Angle

Model Summary

Table 10 Model summary for ANOVA analysis (2 way)

\begin{tabular}{|l|l|l|l|}
\hline S & R-sq & R-sq(adj) & R-sq(pred) \\
\hline 1.69477 & $92.44 \%$ & $81.10 \%$ & $35.70 \%$ \\
\hline
\end{tabular}

Coded Coefficients

\begin{tabular}{|l|l|l|l|l|l|l|}
\hline Term & Effect & Coef & $\begin{array}{l}\text { SE } \\
\text { Coef }\end{array}$ & T-Value & P-Value & VIF \\
\hline Constant & & 402.05 & 1.01 & 397.89 & 0.000 & \\
\hline Cutting Speed & 4.142 & 2.071 & 0.958 & 2.16 & 0.074 & 2.84 \\
\hline Feed Rate & 1.504 & 0.752 & 0.958 & 0.79 & 0.462 & 2.84 \\
\hline Rake Angle & 3.849 & 1.924 & 0.958 & 2.01 & 0.091 & 2.84 \\
\hline $\begin{array}{l}\text { Cutting Speed* } \\
\text { Cutting Speed }\end{array}$ & - & -1.235 & 0.953 & -1.30 & 0.243 & 1.00 \\
\hline $\begin{array}{l}\text { Feed Rate* Feed } \\
\text { Rate }\end{array}$ & 2.188 & 1.094 & 0.953 & 1.15 & 0.295 & 1.00 \\
\hline $\begin{array}{l}\text { Rake Angle* Rake } \\
\text { Angle }\end{array}$ & 0.287 & 0.143 & 0.953 & 0.15 & 0.885 & 1.00 \\
\hline $\begin{array}{l}\text { Cutting Speed* } \\
\text { Feed Rate }\end{array}$ & -4.51 & -2.26 & 1.29 & -1.76 & 0.130 & 2.84 \\
\hline $\begin{array}{l}\text { Cutting Speed * } \\
\text { Rake Angle }\end{array}$ & -5.90 & -2.95 & 1.29 & -2.29 & 0.062 & 2.84 \\
\hline $\begin{array}{l}\text { Feed Rate*Rake } \\
\text { Angle }\end{array}$ & 1.28 & 0.64 & 1.29 & 0.50 & 0.637 & 2.84 \\
\hline
\end{tabular}




\subsection{Model Equation}

\section{Regression Equation}

Stress $=3.86+0.0424$ Cutting Speed -9.0 Feed Rate +1.24 Rake Angle -0.000009 Cutting Speed*Cutting Speed + 12.2 Feed Rate*Feed Rate + 0.0102 Rake Angle*Rake Angle - 0.0201 Cutting Speed*Feed Rate -0.002098 Cutting Speed*Rake Angle + 0.57 Feed Rate* Rake Angle.

The adequacy of regression models should be inspected to confirm that the all models have extracted and all relevant information from all simulated cases. If regression equation results are adequate than the distribution of residuals should be normal distribution. For normality test, the Hypotheses are listed below

A. Null Hypothesis: the residual data should follow normal distribution

B. Alternative Hypothesis: the residual data does not follow a normal distribution Normal probability figures for all responses are shown in figure 3.

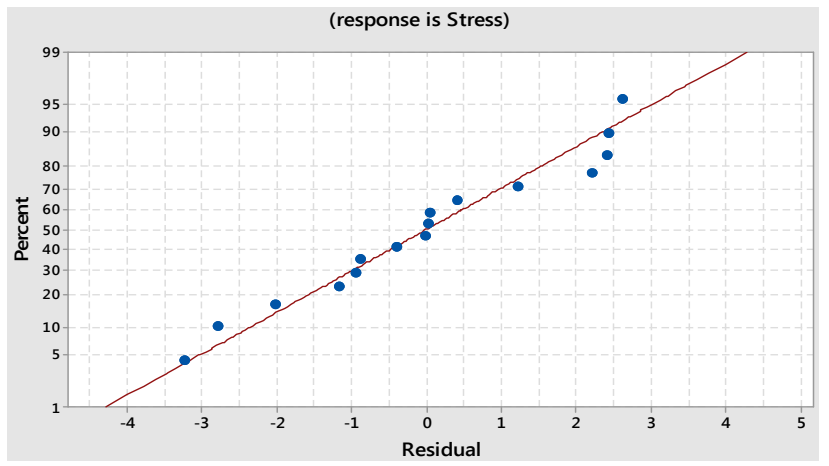

Fig. 3 Normal probability for Von-Misses Stress

\section{Conclusion}

The main aim of this study is to try to make balance among response results and FEM simulation results for single point cutting machining process. This study utilizes L27 orthogonal array for FEM based data analysis. In this study the Analysis of variance (ANOVA), and linear regression analysis is the main key techniques to show response and factor relations strongly with each other. Main results are summarized as follows:

1. Best parameter combination for Finite Element Method results are following respectively

2.

Case_1 best Set (S/N Ratio): A1 B2 C1

Case_1 best Set (Mean ratio): A1 B2 C1 
Table 11 Summary of best cases for S/N ratio and Mean

\begin{tabular}{|c|c|c|c|}
\hline Design & cutting_speed & Feed_Rate & Rake Angle \\
\hline S/N ratio & 250 & 0.8 & 0.0 \\
\hline mean & 250 & 0.8 & 0.0 \\
\hline
\end{tabular}

3. Signal to noise ratio predict a rank for most responsible factors for fill time and volumetric shrinkage and are following for design respectively

Table 12 The response table for $\mathrm{S} / \mathrm{N}$ ratio for Case_1

\begin{tabular}{|c|c|c|c|}
\hline Level & cutting_speed & Feed_Rate & Rake_Angle \\
\hline 1 & -52.04 & -52.05 & -52.02 \\
\hline 2 & -52.07 & -52.03 & -52.06 \\
\hline 3 & -52.12 & -52.11 & -52.11 \\
\hline 4 & -52.11 & -52.14 & -52.16 \\
\hline Delta & 0.08 & 0.11 & 0.14 \\
\hline Rank & 3 & 2 & 1 \\
\hline
\end{tabular}

4. Model equations for stress response is predict accurately with Minitab software and show $90 \%$ good prediction for responses and can be used by any cutting based machining process manufacturer.

\section{REFERENCES}

[1] M.Mahnama, M.R Movahhedy 2012, 'Application of FEM Simulation of chip formation to stability Analysis in orthogonal cutting Process', Journal of Manufacturing Processes Vol.188-194.

[2] J.Lorentzon, N.Jarvstrat, B.L Josefson, 2009,' Modeling chip formation of alloy 718', Journal of Material Processing Technology vol. 4645-4653.

[3] C.Dumitras, I.Cozminca, C.Ungureanu, M.Mihailide, Oct 2008, 'A Finite Element Analysis of the cutting Insert Geometry Influence in Machining Hard Material', Machine Tools and Cutting Tool Design Department, Technical University, Gh.Asachi, Romania.

[4] E.Uhimann, M.Graf Von der Schulenburg, R.Zettier, 2007,'Finite Element Modeling and Cutting Simulation of Inconel 718', Institute of Machine Tools and Factory Management, Techische Universitat, Germany, Vol.56/1/2007.

[5] S.H Rathod, Mohd. Razik, 2013,' Review Study on Finite Element Analysis of Single Point Cutting Tool', International Journal of Engineering Research and Development, Vol. 9, PP.11-14.

[6] L.J Xie, J.Schmidt, C.Schmidt, F.Biesinger, 2005, '2D FEM estimate of tool wear in turning operation, institute for werkstoffkunde', Germany.

[7] Dr.Maan Aabid Tawfiq, Suha Kareem Shahab,2006, A finite element analysis of orthogonal machining using different tool edge geometries, Eng. \& technology Vol.25.

[8] J.S.Strenkowski, J.T Caroll, A finite element model of orthogonal metal cutting, J Engrg Ind. 107 (1985) 349-354.

[9] T.D Marusich, M.Ortiz, Modeling and Simulation of high Speed, Machining, Int.J.Numer. Meth. Engrg 38(1995) 3675-3694.

[10] T.J.R Hughes, The Finite Element Method, Linear Static and Dynamic Finite Element Analysis. Prentice Hall. 1987. 